\title{
Vismodegib for periocular basal cell carcinoma: an international multicentre case series
}

\author{
H. Oliphant ${ }^{1,2} \cdot$ J. Laybourne ${ }^{3} \cdot$ K. Chan ${ }^{4} \cdot$ A. Haridas ${ }^{5} \cdot$ M. R. Edmunds ${ }^{5} \cdot$ D. Morris ${ }^{5}$ L. Clarke ${ }^{6}$ M. Althaus ${ }^{6}$. \\ P. Norris ${ }^{7} \cdot$ M. Cranstoun ${ }^{8} \cdot$ T. J. Sullivan ${ }^{8} \cdot$ S. N. Rajak ${ }^{1,2}$
}

Received: 30 December 2019 / Revised: 17 January 2020 / Accepted: 17 January 2020 / Published online: 29 January 2020

(c) The Author(s), under exclusive licence to The Royal College of Ophthalmologists 2020

\begin{abstract}
Introduction Vismodegib (Erivedge, Genentech) is a first-in-class inhibitor of the hedgehog (Hh) pathway, which is licensed for use in locally advanced basal cell carcinoma (BCC) and metastatic BCC. The National Institute for Health and Care Excellence withdrew recommendation for use of vismodegib secondary to a lack of data comparing vismodegib to standard supportive care. The purpose of this multicentre, international case series is to report outcomes of patients with locally advanced periocular BCC who have been treated with vismodegib.

Methods The medical records of all patients treated with vismodegib were retrospectively reviewed across seven institutions in the United Kingdom, Australia, and New Zealand.

Results Thirteen patients were identified. Seven (54\%) patients were male. All BCCs were ill-defined, with seven (58\%) having orbital involvement at presentation. Median treatment time was 7 months (range 2-36 months). Eleven out of 13 patients developed side effects, the most common being fatigue in six patients (46\%). Median follow-up was 24 months (range 12-48 months). Complete response was found in 5/13 patients (38\%) and a partial response in 8/13 patients (62\%). Six patients had further surgery after vismodegib, with three classed as globe-sparing operations. Three patients developed recurrence $(23 \%)$. Three patients (23\%) ultimately underwent exenteration.

Discussion This study demonstrates vismodegib to be a well-tolerated treatment which may, in some cases, facilitate globesparing surgery and hence avoid disfiguring operations such as exenteration. Uncertainty does remain regarding the longterm outcomes of patients treated with vismodegib.
\end{abstract}

\section{Introduction}

Vismodegib (Erivedge, Genentech) is a first-in-class inhibitor of the hedgehog (Hh) pathway, which received

This work was presented in part at the British Oculoplastic Surgery Society in London 2017 and the European Society of Ophthalmic Plastic and Reconstructive Surgery Hamburg 2019.

H. Oliphant

huw.oliphant@nhs.net

1 Sussex Eye Hospital, Brighton Sussex University Hospital, Eastern Road, Brighton BN2 5BF, UK

2 Brighton and Sussex Medical School, Falmer, Brighton BN1 9PX, UK

3 Manchester Royal Eye Hospital, Oxford Road, Manchester M13 9WL, UK

4 Department of Ophthalmology, 23 Mein Street, Newtown, Wellington 6021, New Zealand approval from the federal drugs authority in the United States of America in January 2012. It was licensed for both locally advanced basal cell carcinoma (BCC) not amenable to surgical intervention, and for metastatic BCC [1-3]. Vismodegib acts via direct inhibition of the protein-coupled receptor smoothened, and inhibits downstream signalling pathways involving transcription factors such as Gli1 [1].

5 Cardiff Eye Unit, University Hospital of Wales, Heath Park Way, Cardiff CF14 4XW, UK

6 Newcastle Eye Centre, Royal Victoria Infirmary, Queen Victoria Road, Newcastle Upon Tyne NE1 4LP, UK

7 Department of Oral and Maxillofacial Surgery, Queen Victoria Hospital, Holtye Road, East Grinstead RH19 3DZ, UK

8 Department of Ophthalmology, The Royal Brisbane and Women's Hospital, Herston, QLD, Australia 
In 2017, the National Institute for Health and Care Excellence (NICE) withdrew its recommendation for the use of vismodegib for the treatment of BCC, citing a lack of survival data in locally advanced disease, and inadequate data comparing outcomes to standard supportive care, with vismodegib having a significantly higher cost per qualityadjusted life year. However, vismodegib continues to be widely used in other countries for cases of locally advanced and metastatic BCC. It has also been shown to have utility in locally advanced periocular BCC [4-10].

The purpose of this multicentre, international case series is to report outcomes of patients with locally advanced periocular BCC who have been treated with vismodegib.

\section{Patients and method}

A retrospective review of clinical case notes was performed for all patients by the identifying institution. All cases of vismodegib treatment for periocular $\mathrm{BCC}$ in the following institutions were included in this study: The Sussex Eye Hospital (Brighton, UK), Manchester Royal Eye Hospital (Manchester, UK), Cardiff Eye Unit (Cardiff, UK), Newcastle Eye Centre (Newcastle, UK), Queen Victoria Hospital (East Grinstead, UK), Wellington Hospital (New Zealand), and the Royal Brisbane and Women's Hospital (Brisbane, Australia). Baseline data for each patient included age, sex, race/ethnicity, BCC subtype, primary location and laterality, primary or recurrence, presence of orbital extension, presence of metastatic disease and ophthalmic signs (vision/motility/lacrimal apparatus involvement).

The dose, duration, compliance, response to treatment and side effects of vismodegib treatment were collected, as well as prior and adjuvant and post-vismodegib surgical treatment and histopathological findings. A complete response to treatment was defined as complete regression of the tumour. A partial response was defined as regression of tumour but not to the extent of a complete response.

The Human Research Authority online decision-making tool determined that ethics approval was not required for this retrospective review.

\section{Results}

\section{Demographics}

Thirteen patents were identified in this retrospective review. Nine patients were from UK institutions, three from the Royal Brisbane and Women's Hospital (Australia), and a further one patient from Wellington, New Zealand.
Seven patients were male and six female. The mean age was 75 (median 76, range 43-91). All patients were Caucasian (Table 1).

\section{Basal cell carcinoma characteristics}

Seven patients had disease centred on or around the medial canthus. Three patients had disease centred on or around the lower eyelid, and one patient had BCC on both the upper and lower eyelid. One patient had disease arising from the forehead and extending down to the superior orbit, and a further patient had disease centred around the right temple region extending to the lateral canthus.

All lesions were ill-defined with $5 / 13$ being described as ulcerating. All lesions were biopsy-confirmed BCC with histopathological subtypes of infiltrative (4), nodular (3), nodular/infiltrative (1), micronodular/infiltrative (1), basosquamous (1) (BSCC), superficial (1) and cystic (1) and one not available (NA).

In $8 / 13$ cases $(62 \%)$ the BCC was recurrent after previous surgery and the disease was primary in the other five cases. One patient had basal cell nevus syndrome.

Orbital involvement was demonstrated in seven patients (58\%) on magnetic resonance imaging. No patients had metastatic disease.

\section{Co-existing ophthalmic signs}

The best corrected visual acuity was mildly reduced in $4 / 13$ (31\%) patients and one had no perception of light vision on the affected side. The ocular motility was impaired in $5 / 13$ (42\%), all of whom had orbital involvement. The lacrimal apparatus was involved in $4 / 13$ cases (38\%).

\section{Vismodegib treatment}

All patients received a vismodegib dose of $150 \mathrm{~g}$ once daily. Compliance was reported as $>90 \%$ in eight cases, with data for the remaining five unavailable. One patient had to stop treatment due to side effects after 2 months.

The mean treatment time with vismodegib was 7 months (range 2-36 months, median 7 months).

\section{Side effects}

Eleven out of 13 patients (85\%) reported side effects secondary to treatment. Reported symptoms were: fatigue (6/13), dysgeusia (4/13), weight loss (3/13), reduced appetite (2/13), muscle cramps (2/13), alopecia (2/13), flatulence $(1 / 13)$. 


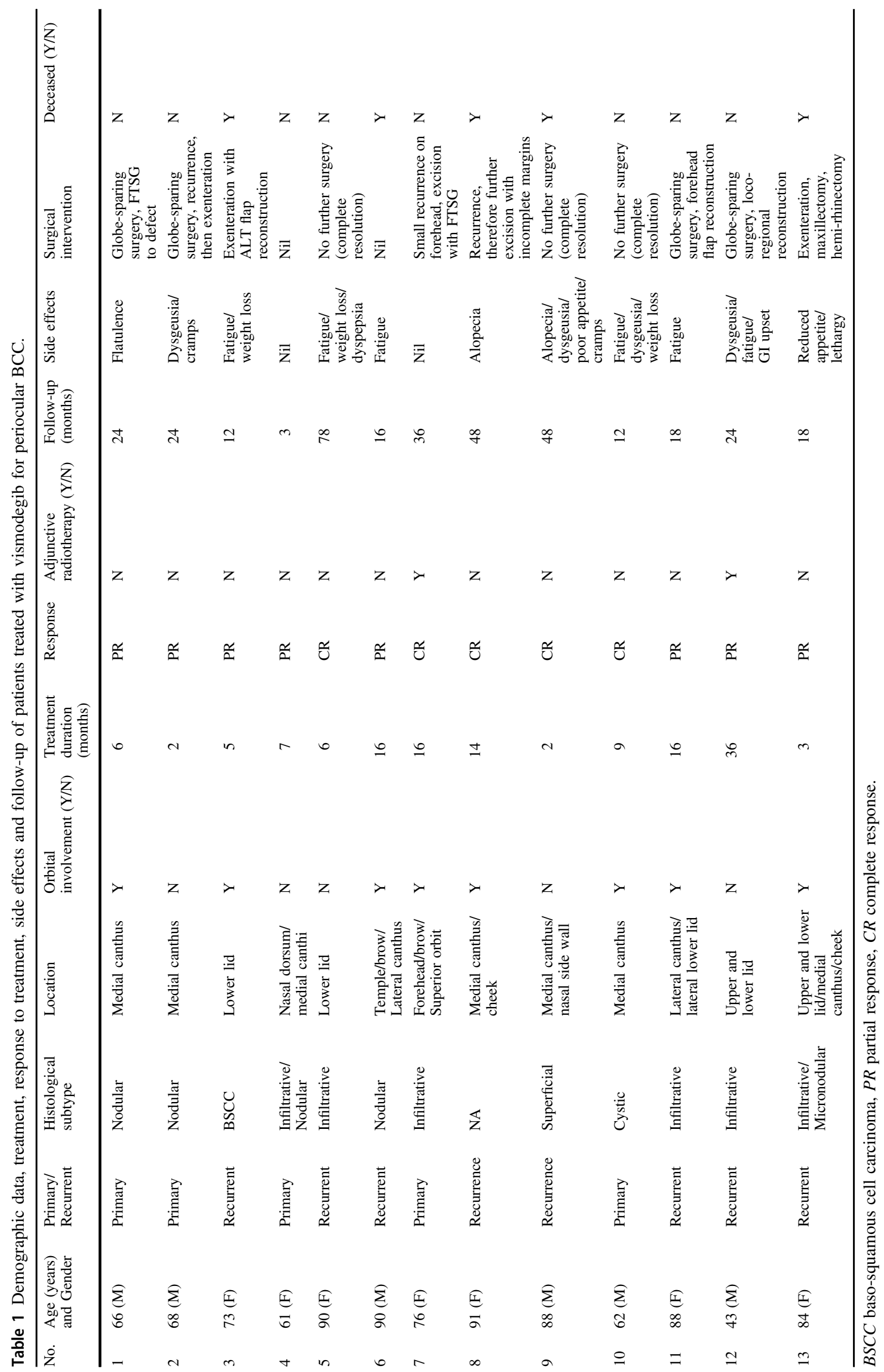




\section{Prior treatment}

Eight out of 13 patients (62\%) had received prior treatment for BCC before commencing vismodegib therapy. Seven of these eight had undergone excision, of which three also had adjunctive radiotherapy. One patient had received cryotherapy alone.

\section{Outcomes}

\section{Follow-up}

The patients were followed for between 12 and 48 months (mean 30 months, median 24 months).

\section{Response to vismodegib}

A complete response to treatment was reported in $5 / 13$ (38\%) patients and a partial response in eight (62\%) patients. In one of the eight patients with a partial response initially, progression was then seen and the patient underwent radiotherapy.

\section{Subsequent surgical treatment}

Out of 13 patients, six patients had tumour excision surgery following the initial course of vismodegib (such as Fig. 1). Three patients underwent exenteration surgery; in one of these the procedure was conducted on cessation of vismodegib, because the tumour had not regressed sufficiently to alter the original surgical plan. In the other two globesparing surgery was initially undertaken, but exenteration was subsequently conducted for later recurrence. The remaining three patients had cutaneous excisions, of whom one had had orbital involvement prior to vismodegib treatment but significant regression facilitated pre-septal surgery.

\section{Recurrence}

Recurrent BCC occurred in 3/13 (23\%) patients after either vismodegib treatment alone or vismodegib treatment with post-treatment surgical excision. One of these patients developed recurrence on the sclera following globe-sparing surgery and loco-regional flap reconstruction, and subsequently underwent exenteration. It is unclear in this patient whether the recurrence was from the original visible tumour site (medial canthus) or from a deep seated focus of tumour. One patient demonstrated an apparent complete regression of the tumour from vismodegib treatment, but then developed a small recurrence on the forehead (original primary site) necessitating excision and reconstruction with a full thickness skin graft. The third patient had 3 months of vismodegib treatment followed by local resections using Mohs micrographic surgery with apparently clear margins, but subsequently developed recurrence. This patient had a further 2 months of vismodegib treatment, but there was minimal response, so underwent exenteration.

\section{Discussion}

In this study we report a partial or complete response to vismodegib in all 13 patients with locally advanced periocular and orbital BCC, and in five cases the treatment obviated the need for surgical excision of the tumour. However, 11 patients suffered significant side effects from the vismodegib treatment and exenteration was still required in three patients.

There is an increasing body of evidence on the outcomes of vismodegib for non-periocular BCC with studies reporting between $60 \%$ partial response rates up to $68.5 \%$ complete response rates [1-3]. There is a paucity of data on the outcomes of vismodegib treatment for locally advanced periocular BCC. Small prospective and retrospective series report complete response rates between 25 and $67 \%$ with only $13 \%$ showing no response in one study [5-7]. In the present series $38 \%$ (five patients) demonstrated a complete response to vismodegib, with the rest demonstrating a partial response.

Prolonged vismodegib treatment may cause significant side effects and necessitate cessation of treatment. The STEVIE study (The SafeTy Events in VIsmodEgib study) reported muscle cramps (in 7\% of patients), dysgeusia (5\%), weight loss (4\%), alopecia (3\%), asthenia(3\%), fatigue

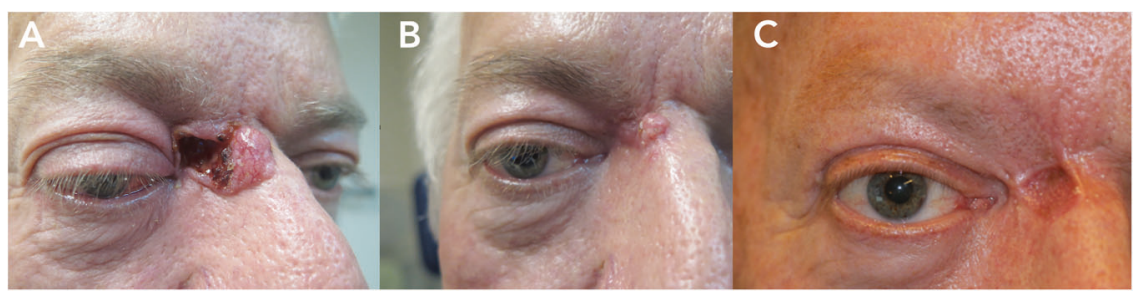

Fig. 1 Example of tumour regression following course of vismodegib and subsequent resection and reconstruction with full thickness skin graft. Male patient with medial canthal/bridge of nose BCC at presentation (a), treated with vismodegib showing partial response (b). Subsequent resection and reconstruction with no recurrence at 2 years $(\mathbf{c})$. 
(2\%), ageusia (2\%) and nausea (1\%) [3]. Data from the ERIVANCE trial suggested a higher incidence of adverse events, particularly muscle spasm, when treatment lasted more than 12 months. Hepatotoxicity which has been described in association with vismodegib was not seen in any of the patients in this series. It is not clear why the side effect profile was different in the present series in which fatigue was reported by nearly half the patients and dysgeusia in nearly a third (but only one patient had to stop treatment) but it may reflect the long duration of treatment (mean 10 months) or increasing awareness of potential side effects and subsequent specific questioning of patients.

Surgery is the mainstay of treatment for BCC with orbital invasion. Exenteration is frequently required and is a disfiguring operation that carries significant surgical and psychological morbidity $[11,12]$. Adjunctive radiotherapy may be beneficial in some cases, though may also cause sight threatening ocular surface disease negating the major benefit of globe-sparing surgery and may hinder socket recovery after exenteration. Globe-sparing surgery can be utilised, but is still a major surgical intervention that can result in intractable diplopia, epiphora, and lid malposition and may not achieve complete excision margins [13]. In the present study, vismodegib treatment achieved sufficient tumour reduction in 3 of 13 patients enabling globe-sparing excision surgery instead of the anticipated exenteration. In a further patient, the apparent reduction in tumour size from the vismodegib was falsely reassuring as globe-sparing surgery was attempted, but clear margins were not attained, and subsequent recurrence on the sclera necessitated exenteration.

Despite some of the beneficial responses in this and other series, there remain areas of great uncertainty in vismodegib treatment combined with huge variation in individual treatment response. For example evidence is lacking for (1) the optimal treatment duration, (2) how to assess treatment response, (3) predictors for the degree of response to treatment of individual patients (4) which tumours will truly reduce in size throughout their margin and which will showed patchy reduction leaving tumour foci throughout the original area that may be harder to delineate and excise (5) to what degree tumours develop treatment resistance [14, 15].

This is a retrospective study and may be affected by recall bias, although the small number of patients treated in each unit combined the complexity and extended nature of treatment may reduce this. In addition, patients in this series come from two continents. Whilst all patients included in this study were Caucasian, it is possible that environmental factors, such as ultraviolet exposure or genetics may influence the nature of the tumour and its response to treatment.

This retrospective review demonstrates vismodegib to be an effective, safe and well-tolerated adjunctive treatment for advanced periocular and orbital BCC. It may obviate the need for radical and disfiguring surgery such as orbital exenteration in selected patients.

\section{Summary}

\section{What was known before}

- Vismodegib has previously been shown to have utility in periocular BCC although data regarding outcomes is limited.

- Recommendation for use of vismodegib was recently withdrawn by NICE due to a lack of evidence regarding versus standard supportive care.

\section{What this study adds}

- Vismodegib appears to be of use in selected patients and may obviate the need for major and disfiguring surgery such as exenteration.

- Vismodegib appears to be well tolerated in this group of patients with fatigue being the most common side effect.

\section{Compliance with ethical standards}

Conflict of interest The authors declare that they have no conflict of interest.

Publisher's note Springer Nature remains neutral with regard to jurisdictional claims in published maps and institutional affiliations.

\section{References}

1. Sekulic A, Migden MR, Oro AE, Dirix L, Lewis KD, Hainsworth JD, et al. Efficacy and safety of vismodegib in advanced basal-cell carcinoma. N. Engl J Med. 2012;366:2171-9.

2. Sekulic A, Migden MR, Basset-Seguin N, Garbe C, Gesierich A, Lao CD, et al. Long-term safety and efficacy of vismode- gib in patients with advanced basal cell carcinoma: final up- date of the pivotal ERIVANCE BCC study. BMC Cancer. 2017;17:332. https://doi.org/10.1186/s12885-017-3286-5.

3. Basset-Seguin N, Hauschild A, Kuntsfield R, Grob J, Dreno B, Mortier L, et al. Vismodegib in patients with advanced basal cell carcinoma: primary analysis of STEVIE, an international, openlabel trial. Our J Cancer. 2017;86:334-48. https://doi.org/10.1016/ j.ejca.2017.08.022.

4. Gill HS, Moscato EE, Chang AL, Soon S, Silkiss RZ. Vismodegib for periocular and orbital basal cell carcinoma. JAMA Ophthalmol. 2013;131:1591-4.

5. Sagiv O, Nagarajan P, Ferrarotto R, Kandi TJ, Thakar SD, Glisson $\mathrm{BS}$, et al. Ocular Preservation with neoadjuvant vismodegib in patients with locally advanced periocular basal cell carcinoma. $\mathrm{Br}$ J Ophthamol. 2019;103:775-80.

6. Eiger-Moscovich M, Reich E, Tauber G, Berliner O, Priel A, Ben Simon G, et al. Efficacy of vismodegib for the treatment of 
orbital and advanced periocular basal cell carcinoma. Am J Ophthalmol. 2019;207:62-70. https://doi.org/10.1016/j.ajo. 2019.04.013.

7. Wong KY, Fife K, Lear JT, Price RD, Durrani AJ. Vismodegib for locally advanced periocular and orbital basal cell carci- noma: a review of 15 consecutive cases. Plast Reconstr Sur Glob Open. 2017;5:e1424.

8. Hogarty DT, Dewhurts NG, Burt B. Vismodegib and orbital excision for treating locally advanced basal cell carcinoma. Int Med Case Rep J. 2018;11:177-9. https://doi.org/10.2147/IMCRJ.S168666.

9. Mathis J, Doerr T, Lin E, Ibrahim SF. Oral hedgehog pathway inhibition as a means for ocular salvage in locally advanced intraorbital basal cell carcinoma. Dermatol Surg. 2019;45:17-25. https://doi.org/10.1097/DSS.0000000000001640.

10. Ozgur OK, Yin V, Chou E, Ball S, Kies M, William WN, et al. Hedgehog pathway inhibi- tion for locally advanced periocular basal cell carcinoma and basal cell nevus syndrome. Am J Ophthalmol. 2015;160:220-7.e2.
11. Leibovitch I, Mcnab A, Sullivan T, Davids G, Selva D. Orbital invasion by periocular basal cell carcinoma. Ophthalmology. 2005;112:717-23.

12. Rahman I, Cook AE, Leatherbarrow B. Orbital exenteration: a 13 year Manchester experience. Br J Ophthalmol. 2005;89:1335-40.

13. Madge SN, Khine AA, Thaller VT, Davis G, Malhotra R, McNab A, et al. Globe-sparing surgery for medial canthal Basal cell carcinoma with anterior orbital invasion. Ophthalmology. 2010;117:2222-8. https://doi.org/10.1016/j.ophtha.2010.02.013.

14. Pricl S, Cortelazzi B, Dal Col V, Marson D, Laurini E, Fermeglia $\mathrm{M}$, et al. Smoothened (SMO) receptor mutations dictate resistance to vismodegib in basal cell carcinoma. Mol Oncol. 2015;9:389-97.

15. Brinkhuizen T, Reinders MG, vanGeel M, Hendriksen AJ, Paulussen $\mathrm{AD}$, Winnepenninckx VJ, et al. Acquired resistance to the Hedgehog pathway inhibitor vismodegib due to smoothened mutations in treatment of locally advanced basal cell carcinoma. $\mathrm{J}$ Am Acad Dermatol. 2014;71:1005-8. 